\title{
Assessment of CD- 105 as an Angiogenic Modulator in Odontogenic Myxomas and Dental Follicles
}

\author{
María del Carmen González-Galván, MSc', José Manuel Aguirre-Urizar, PhD', \\ Ronell Bologna-Molina, $\mathbf{P h D}^{2}$, J. Eduardo Farfán-Morales, $\mathbf{M L S}^{3}$, \\ Maria Luisa Gainza-Cirauqui, $\mathrm{PhD}^{4}, \mathrm{Xabier}^{5}$ Marichalar-Mendia, PhD', \\ and Adalberto Mosqueda-Taylor, $\mathrm{MSc}^{5}$
}

\begin{abstract}
Aim. Odontogenic myxoma is a benign intraosseous neoplasm of the jaws, with a locally aggressive behavior and a high recurrence rate. CD-I05 is a homodimeric cell membrane glycoprotein and is a component of the TGF- $\beta$ I growth factor receptor complex that modulates angiogenesis by regulating the proliferation, differentiation and cellular migration. The aim of this study is to quantify the microvascular density of the odontogenic myxoma based on the expression of CD-105. Materials and Methods. The analysis included 18 odontogenic myxoma and 18 dental follicles as controls. A standard immunohistochemical procedure was performed with the CD-105 antibody. Five representative fields (40x) of the odontogenic myxoma and the dental follicles were selected to determine the microvascular density, which was then followed by a descriptive and comparative statistical analysis. Results. Dental follicles presented a significantly higher microvascular density compared with odontogenic myxoma $(P=.001)$. The odontogenic myxoma smaller than $3 \mathrm{~cm}$ showed a greater microvascular density than those larger than $3 \mathrm{~cm}$ in size $(P>.05)$, and the microvascular density was lower in large odontogenic myxomas as compared with the dental follicles $(P=.003)$. Conclusion. A weaker expression of CD-105 in odontogenic myxoma might indicate a lower angiogenic activity, suggesting that vascular proliferation has a limited role in the growth mechanisms and in the aggressive behavior of this neoplasm.
\end{abstract}

\section{Keywords}

CD-105, dental follicle, microvascular density, odontogenic myxoma

\section{Introduction}

Odontogenic myxoma $(\mathrm{OM})$ is a benign intraosseous neoplasm of the jaws with a locally aggressive behavior and a high recurrence rate. ${ }^{1-3}$ Its frequency ranges from $2.2 \%$ to $17.7 \%$ of all odontogenic tumors. ${ }^{4-7}$ This tumor develops within a wide age range, with a greater incidence during the second and third decades, and has a 2 to 1 predilection for females. Two-thirds of the cases are located in the mandible, developing as a slow, progressive and generally asymptomatic tumoral growth. ${ }^{1-3,5}$ It has a marked potential to infiltrate and destroy bone, and a high recurrence rate. - $^{8-10}$

Among the possible mechanisms of growth of OM, the increase in cellular proliferation, ${ }^{11-13}$ the decrease in apoptosis, ${ }^{11-13}$ the production of extracellular matrix degrading enzymes, ${ }^{11,14,15}$ the accumulation of orosomucoid-1 in the extracellular matrix, ${ }^{16,17}$ the induction to bone reabsorption, ${ }^{18}$ and the increase in angiogenesis and production of the vascular endothelial growth factor-A (VEGF-A $)^{17}$ have been considered.
CD-105 is a homodimeric cell membrane glycoprotein, component of the growth factor $\beta 1$ (TGF- $\beta 1$ ) receptorcomplex that modulates angiogenesis by regulating the proliferation, differentiation and endothelial cell migration. $^{19-21}$ The expression of CD-105 is a characteristic property of the newly formed blood vessels as there is a lack of its expression in previously-existing blood and lymphatic vessels. ${ }^{19,20,22}$

\footnotetext{
'University of the Basque Country (UPV/EHU), Vizcaya, Spain

${ }^{2}$ Universidad de la Republica (UDELAR), Montevideo, Uruguay

${ }^{3}$ Hospital General "Dr Dario Fernandez Fierro" ISSSTE, Mexico City, Mexico

${ }^{4}$ University of Malta, Malta

${ }^{5}$ Universidad Autónoma Metropolitana-Xochimilco, Mexico City, Mexico
}

Corresponding Author:

María del Carmen González Galván, Departamento de Estomatología Unidad de Patología Oral y Maxilofacial, Universidad del País Vasco/ EHU, Barrio Sarriena s/n 48950 Leioa, Vizcaya, Spain.

Email: maricarmen_galvan@hotmail.com 
The quantification of the expression of this protein has been proposed to evaluate neoangiogenesis in different types of tumors. ${ }^{21,23}$ On the other hand, microvascular density (MVD) is a useful histomorphological parameter to evaluate tumor angiogenesis, which is considered an indicator of tumor growth, and has been correlated with the aggressive behavior of tumors. ${ }^{17,20,22}$

The aim of this study was to compare the MVD in OM and dental follicle (DF) based on the expression of CD-105, in an effort to obtain new information that may contribute to understand the possible pathogenic mechanisms implicated in the growth of this neoplasm.

\section{Materials and Methods}

Tissue samples from inflammation-free areas of $18 \mathrm{OM}$ (10 female and 8 male; with a mean age of 32.83 years; range 10-53 years) and of 18 DF free of inflammation (9 female and 9 male; with a mean age of 14.4 years; range 9-22 years) diagnosed in the Oral Pathology Laboratory of the Universidad Autónoma Metropolitana Xochimilco and in a private service of oral pathology diagnosis in Mexico City.

This study was approved by the Research Committee of the Biological and Health Sciences Division of the Universidad Autonóma Metropolitana Xochimilco.

Relevant information on the size of the OMs included in this study was obtained from the clinical files. The histopathological diagnosis of each case was confirmed on hematoxylin and eosin-stained sections and was based on the microscopic criteria included in the current World Health Organization histological classification of tumors. ${ }^{24}$ The OMs were classified according to their size at diagnosis as small odontogenic myxomas (SOM), when tumors were up to $3 \mathrm{~cm}(\mathrm{n}=4)$, and as large odontogenic myxomas (LOM) when they were larger than $3 \mathrm{~cm}(\mathrm{n}=14)$.

Two micrometer-thick sections from each paraffin block were deparaffinized, rehydrated and treated with 0.1 $\mathrm{mol} / \mathrm{L}$ sodium citrate $(\mathrm{pH}$ 6.2) to expose the antigenic epitopes. The endogenous peroxidases were blocked with $0.9 \%$ hydrogen peroxide. The primary antibody was incubated in a humidifying chamber (Sequenza Slide Rack) with a 1:50 dilution of the anti-CD-105 polyclonal antibody (BioSB, Santa Barbara, CA, USA) and with the S2022 diluent (DAKO, Carpinteria, CA, USA) for 45 minutes. The reaction was visualized with the Mouse/Rabbit Immunodetector System (BioSB, Santa Barbara, CA, USA) and revealed with the 3,3-diaminobenzidine hydrochloride (DAB) substrate showing as a brown-colored precipitate. The samples were counterstained with Gill's hematoxylin and mounted with a permanent medium (Eukitt).

Three oral pathologists assessed the immunohistochemical expression individually before reaching a consensus. The assessment criteria were based on previous

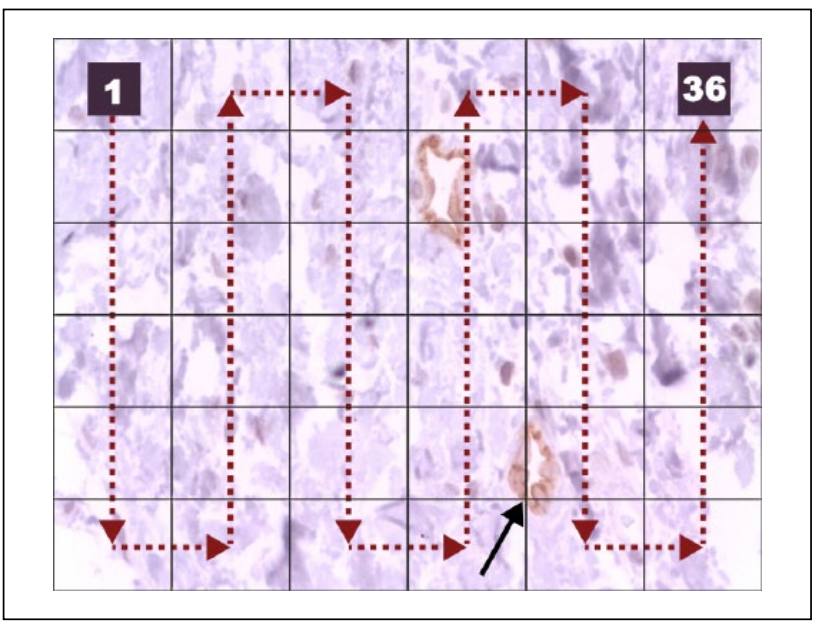

Figure I. Method employed for the microvascular density (MVD) analysis. Note the arrow pointing to the intersection coinciding with the wall of a blood vessel (40x).

Table I. Microvascular Density (MVD) of the OMs and DFs.

\begin{tabular}{|c|c|c|c|c|}
\hline \multirow{2}{*}{$\begin{array}{l}\text { Type of } \\
\text { Lesion }\end{array}$} & \multirow{2}{*}{$\begin{array}{l}\text { Case } \\
\text { No. }\end{array}$} & \multicolumn{3}{|c|}{ MVD } \\
\hline & & Minimum & Maximum & Mean $( \pm S D)$ MVD \\
\hline OM & 18 & 0 & I & $0.29( \pm 0.32)$ \\
\hline SOM & 4 & 0 & 0.8 & $0.4( \pm 0.33)$ \\
\hline LOM & 14 & 0 & 1 & $0.28( \pm 0.32)$ \\
\hline DF & 18 & 0 & 3.4 & $1.27( \pm 1.06)$ \\
\hline
\end{tabular}

Abbreviations: OM, odontogenic myxoma; SOM, small odontogenic myxoma; LOM, large odontogenic myxoma; DF, dental follicle; MVD, microvascular density.

studies. ${ }^{18-20,23,25,26}$ The standardization of the examiners showed a kappa index of 0.88 .

The MVD was analyzed using the method proposed by Vered $\mathrm{t} \mathrm{al}^{27}$ and with the grid suggested by Bologna-Molina et al. ${ }^{28}$ Five microphotographs of the most representative areas at $40 \times$ were taken with a digital camera (Olympus CX 31; Olympus, San Diego, CA, USA). Subsequently, a $6 \times 6$ grid was placed over the photograph to quantify the vessels located in the intersection areas (Figure 1). In cases where the wall or the lumen of the vessel intercepted more than one point, only one was taken into consideration. In each picture, cell counting started in the top left frame of the grid and finished in the top right frame (Figure 1). The number of positive vessels was counted manually in each image. The average of counts in these fields was considered in the analysis. This procedure was followed to obtain the MVD from the OMs and the DFs.

With all the data obtained, a descriptive and comparative analysis was performed using the SPSS version 15.0 software (SPSS Inc, IBM, Armonk, NY). The means of the MVD were compared with the Mann-Whitney $U$ statistical 


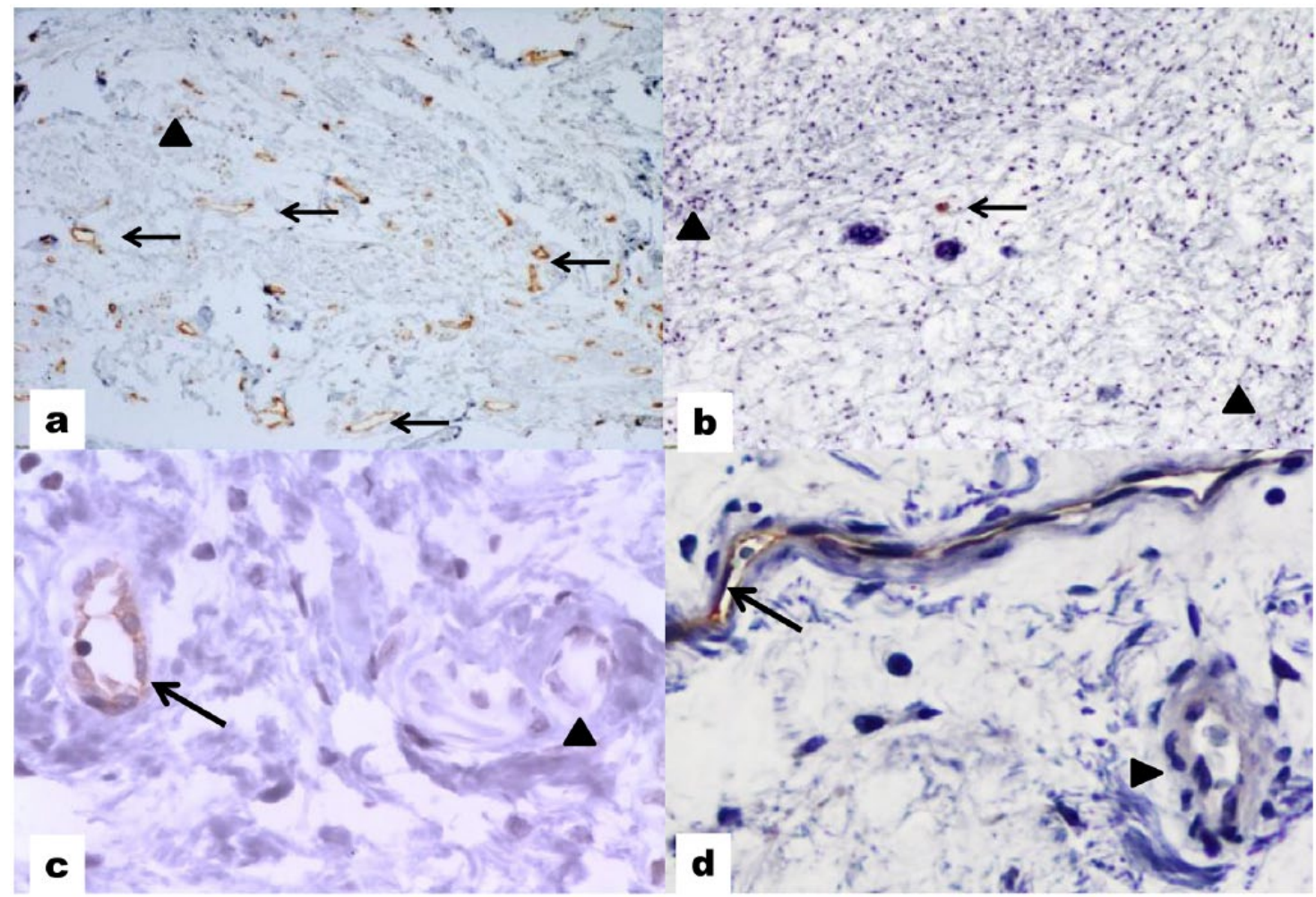

Figure 2. Expression of CD-105 (arrows) in dental follicle (DF) (a 10x, c 40x) and in odontogenic myxoma (OM) (b I0x, d 40x). Note the lack of expression of the marker in mature vessels (arrowheads).

test and the Kruskal-Wallis test. Significance was considered when $P<.05$.

\section{Results}

Table 1 shows the relevant data of the MVD found in the $\mathrm{OM}$ and DF studied cases. There was a significantly higher MVD in DFs as compared with OMs $(P=.001)$. The expression of CD-105 in OMs and DFs is presented in Figure 2, showing the lack of expression of the marker in mature vessels.

Although SOM showed a greater MVD (0.4) than LOM (0.28), this difference was nonsignificant $(P=.521)$. On the other hand, the MVD was lower in LOM as compared with the DFs $(P=.003)$.

\section{Discussion}

Tumor growth requires blood supply to provide oxygen, metabolites and growth factors needed for cell proliferation. Angiogenesis is the process of formation and development of new blood vessels from previously existing vessels; in pathological conditions, this process contributes to tumor growth and favors the development of metastasis.

Various studies ${ }^{18,20,25,26}$ have employed the expression of CD-105 to assess tumor angiogenesis and the MVD in odontogenic tumors, and have demonstrated a greater specificity of CD-105 with respect to other endothelial markers for identification of neoangiogenesis. To our knowledge, this is the first study evaluating tumor angiogenesis in OMs with CD-105.

The increase in MVD is considered an indicator of tumor growth and a positive predictor of metastasis, and is consequently associated with survival and aggressiveness of some neoplasms. ${ }^{20,22}$ Furthermore, it may be used to study the antineoplastic effect of potential angiogenic therapy, even in cases of recurrent or highly aggressive odontogenic tumors. ${ }^{25}$

We consider that the currently available methodology used to quantify angiogenesis through MVD should be standardized with an appropriate and reproducible method in order to be useful for comparing data among different studies. ${ }^{18,25,26}$ Our work followed the method described by Vered et al, ${ }^{27}$ as it is the most simple and user-friendly. We complemented it with the grid described by our group, ${ }^{28}$ 
which, to our understanding, complies with the necessary criteria for objectivity and reproducibility.

We observed in our study that although the OMs and the DFs pose similar histomorphological features, the tumors presented a significantly lower MVD. These results would support previous observations from our group ${ }^{17}$ on the minor role played by angiogenesis in the growth and aggressiveness of this neoplasm, as opposed to what seems to occur with the expression of CD-105 in other odontogenic lesions. ${ }^{18,26}$ In this regard, when comparing the MVD between SOM and LOM, a lower yet nonsignificant MVD was observed in the larger neoplasms, which could be associated with different stages of tumoral growth.

Cell proliferation seem to be low in $\mathrm{OM},{ }^{11-13}$ and thus it has been suggested that the growth of this tumor is based on its water-binding capacity that helps increase the hydrostatic pressure and induce the generation of mechanisms of bone reabsorption. ${ }^{11,13,29}$ Furthermore, a very recent study from our group ${ }^{17}$ demonstrated that the orosomucoid-1 protein is present in $\mathrm{OM}$ and this fact suggest its overexpression might be a contributing factor for the classical viscous and mucoid structural configuration of OM, which, at least partially, is responsible for its invasive nature into the trabecular bone. Furthermore, a correlation between the expression of orosomucoid-1 and VEGF is described, suggesting the participation of both proteins in the mechanism of angiogenesis in this benign neoplasm. ${ }^{17}$

In conclusion, our results suggest that neoangiogenesis plays a minor role in the growth of the OMs and supports the existence of other mechanisms of expansion and progression of this neoplasm.

\section{Declaration of Conflicting Interests}

The author(s) declared no potential conflicts of interest with respect to the research, authorship, and/or publication of this article.

\section{Funding}

The author(s) disclosed receipt of the following financial support for the research, authorship, and/or publication of this article: This study was financially supported by grants from the Department of Education, Universities and Research, Government of the Basque Country (IT-809-13). MC GonzálezGalván is supported by a fellowship from the ITAIPU Binacional-Paraguay.

\section{References}

1. Simon EN, Merkx MA, Vuhahula E, Ngassapa D, Stoelinga PJ. Odontogenic myxoma: a clinicopathological study of 33 cases. Int J Oral Maxillofac Surg. 2004;33:333-337.

2. Li TJ, Sun LS, Luo HY. Odontogenic myxoma: a clinicopathologic study of 25 cases. Arch Pathol Lab Med. 2006;130:1799-1806.
3. Noffke CE, Raubenheimer EJ, Chabikuli NJ, Bouckaert MM. Odontogenic myxoma: review of the literature and report of 30 cases from South Africa. Oral Surg Oral Med Oral Pathol Oral Radiol Endod. 2007;104:101-109.

4. Mosqueda-Taylor A, Ledesma-Montes C, CaballeroSandoval S, Portilla-Robertson J, Ruíz-Godoy Rivera LM, Meneses-García A. Odontogenic tumors in Mexico: a collaborative retrospective study of 349 cases. Oral Surg Oral Med Oral Pathol Oral Radiol Endod. 1997;84:672-675.

5. Buchner A, Merrell PW, Carpenter WM. Relative frequency of peripheral odontogenic tumors: a study of 45 new cases and comparison with studies from the literature. J Oral Pathol Med. 2006;35:385-391.

6. Osterne RL, Brito RG, Alves AP, Cavalcante RB, Sousa FB. Odontogenic tumors: a 5-year retrospective study in a Brazilian population and analysis of 3406 cases reported in the literature. Oral Surg Oral Med Oral Pathol Oral Radiol Endod. 2011;111:474-481.

7. Siriwardena BS, Tennakoon TM, Tilakaratne WM. Relative frequency of odontogenic tumors in Sri Lanka: analysis of 1677 cases. Pathol Res Pract. 2012;208:225-230.

8. Peltola J, Magnusson B, Happonen RP, Borrman H. Odontogenic myxoma a radiographic study of 21 tumours. Br J Oral Maxillofac Surg. 1994;32:298-302.

9. Barker BF. Odontogenic myxoma. Semin Diagn Pathol. 1999;16:297-301.

10. Lo Muzio L, Nocini P, Favia G, Procaccini M, Mignogna MD. Odontogenic myxoma of the jaws: a clinical, radiologic, immunohistochemical, and ultrastructural study. Oral Surg Oral Med Oral Pathol Oral Radiol Endod. 1996;82: 426-433.

11. Bast BT, Pogrel MA, Regezi JA. The expression of apoptotic proteins and matrix metalloproteinases in odontogenic myxomas. J Oral Maxillofac Surg. 2003;61:1463-1466.

12. Iezzi G, Piattelli A, Rubini C, Artese L, Fioroni M, Carinci F. MIB-1, Bcl-2 and p53 in odontogenic myxomas of the jaws. Acta Otorhinolaryngol Ital. 2007;27:237-242.

13. Martínez-Mata G, Mosqueda-Taylor A, Carlos-Bregni R, et al. Odontogenic myxoma: clinico-pathological, immunohistochemical and ultrastructural findings of a multicentric series. Oral Oncol. 2008;44:601-607.

14. Miyagi SP, Hiraki KR, Martins MD, Marques MM. Expression of matrix metalloproteinases 2 and 9 in odontogenic myxoma in vivo and in vitro. J Oral Sci. 2008;50:187-192.

15. Nonaka CF, Goulart Filho JA, Da Costa Miguel MC, De Souza LB, Pinto LP. Immunohistochemical expression of matrix metalloproteinases 1,2 , and 9 in odontogenic myxoma and dental germ papilla. Pathol Res Pract. 2009;205:458-465.

16. García-Muñoz A, Rodríguez MA, Bologna-Molina R, et al. The orosomucoid 1 protein ( $\alpha 1$ acid glycoprotein) is overexpressed in odontogenic myxoma. Proteome Sci. 2012;10:49.

17. Bologna-Molina R, Mosqueda-Taylor A, DomínguezMalagón $\mathrm{H}$, et al. Immunolocalization of VEGF-A and orosomucoid-1 in odontogenic myxoma. Rom $J$ Morphol Embryol. 2015;56:465-473.

18. De Andrade Santos PP, De Aquino AR, Oliveira Barreto A, De Almeida Freitas R, Galvão HC, De Souza LB. 
Immunohistochemical expression of nuclear factor $\kappa \mathrm{B}$, matrix metalloproteinase 9, and endoglin (CD105) in odontogenic keratocysts, dentigerous cysts, and radicular cysts. Oral Surg Oral Med Oral Pathol Oral Radiol Endod. 2011;112:476-483.

19. Yao Y, Pan Y, Chen J, Sun X, Qiu Y, Ding Y. Endoglin (CD105) expression in angiogenesis of primary hepatocellular carcinomas: analysis using tissue microarrays and comparisons with CD34 and VEGF. Ann Clin Lab Sci. 2007;37:39-48.

20. Hande AH, Gadbail AR, Sonone AM, Chaudhary MS, Wadhwan V, Nikam A. Comparative analysis of tumour angiogenesis in solid multicystic and unicystic ameloblastoma by using CD 105 (endoglin). Arch Oral Biol. 2011;56:1635-1640.

21. Miyata Y, Sagara Y, Watanabe S, et al. CD105 is a more appropriate marker for evaluating angiogenesis in urothelial cancer of the upper urinary tract than CD31 or CD34. Virchows Arch. 2013;463:673-679.

22. Saad RS, Liu YL, Nathan G, Celebrezze J, Medich D, Silverman JF. Endoglin (CD105) and vascular endothelial growth factor as prognostic markers in colorectal cancer. Mod Pathol. 2004;17:197-203.

23. Basnaker M, Shashikanth SR, Satish BNVS. Expression of endoglin (CD-105) and microvessel density in oral dysplasia and squamous cell carcinoma. J Clin Diagn Res. 2014;8:91-94.
24. Buchner A, Odell EW. Odontogenic myxoma/myxofibroma. In: Barnes L, Everson JW, Reichart P, Sidransky D, eds. World Health Organization Classification of Tumours. Pathology and Genetics of Head and Neck Tumours. Lyon, France: IARC Press; 2005:316-317.

25. Gadbail AR, Hande A, Chaudhary M, et al. Tumor angiogenesis in keratocystic odontogenic tumor assessed by using CD-105 antigen. J Oral Pathol Med. 2011;40:263-269.

26. Jamshidi S, Zargaran M, Baghaei F, et al. An immunohistochemical survey to evaluate the expression of CD105 and CD34 in ameloblastoma and odontogenic keratocyst. J Dent (Shiraz). 2014;15:192-198.

27. Vered M, Buchner A, Dayan D. Giant cell granuloma of the jawbones - a proliferative vascular lesion? Immunohistochemical study with vascular endothelial growth factor and basic fibroblast growth factor. $\mathrm{J}$ Oral Pathol Med. 2006;35:613-619.

28. Bologna-Molina R, Damián-Matsumura P, Molina-Frechero $\mathrm{N}$. An easy cell counting method for immunohistochemistry that does not use an image analysis program. Histopathology. 2011;59:801-803.

29. Slootweg PJ, van den Bos T, Straks W. Glycosaminoglycans in myxoma of the jaw: a biochemical study. J Oral Pathol. 1985;14:299-306. 